\title{
Tetrakisheteroleptic complexation at porphyrins: a convenient route to diversely functionalized aggregates
}

Michael Schmittel, R. S. K. Kishore

\section{Supporting Information}

a) ESI MS spectra of selected compounds

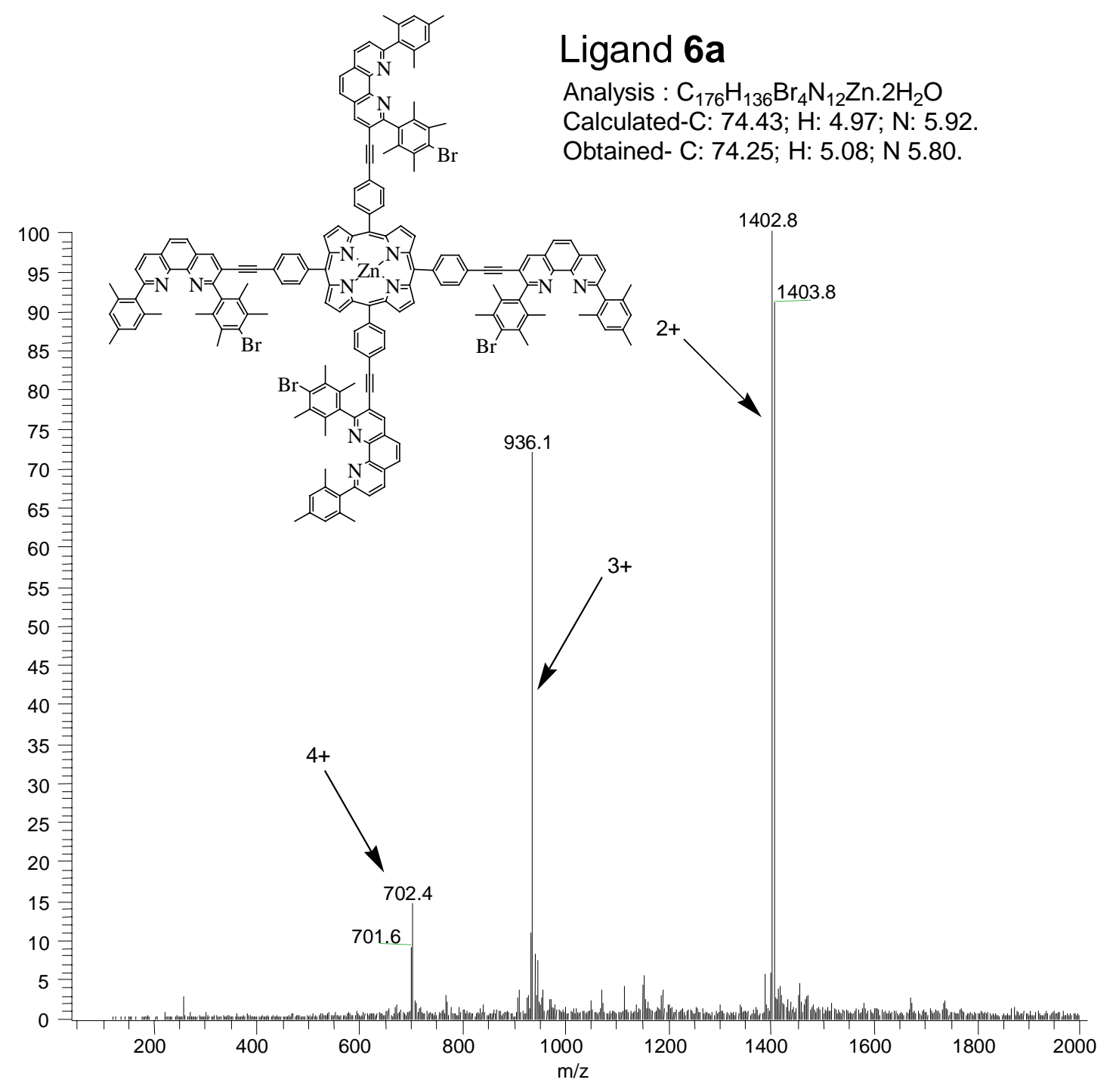




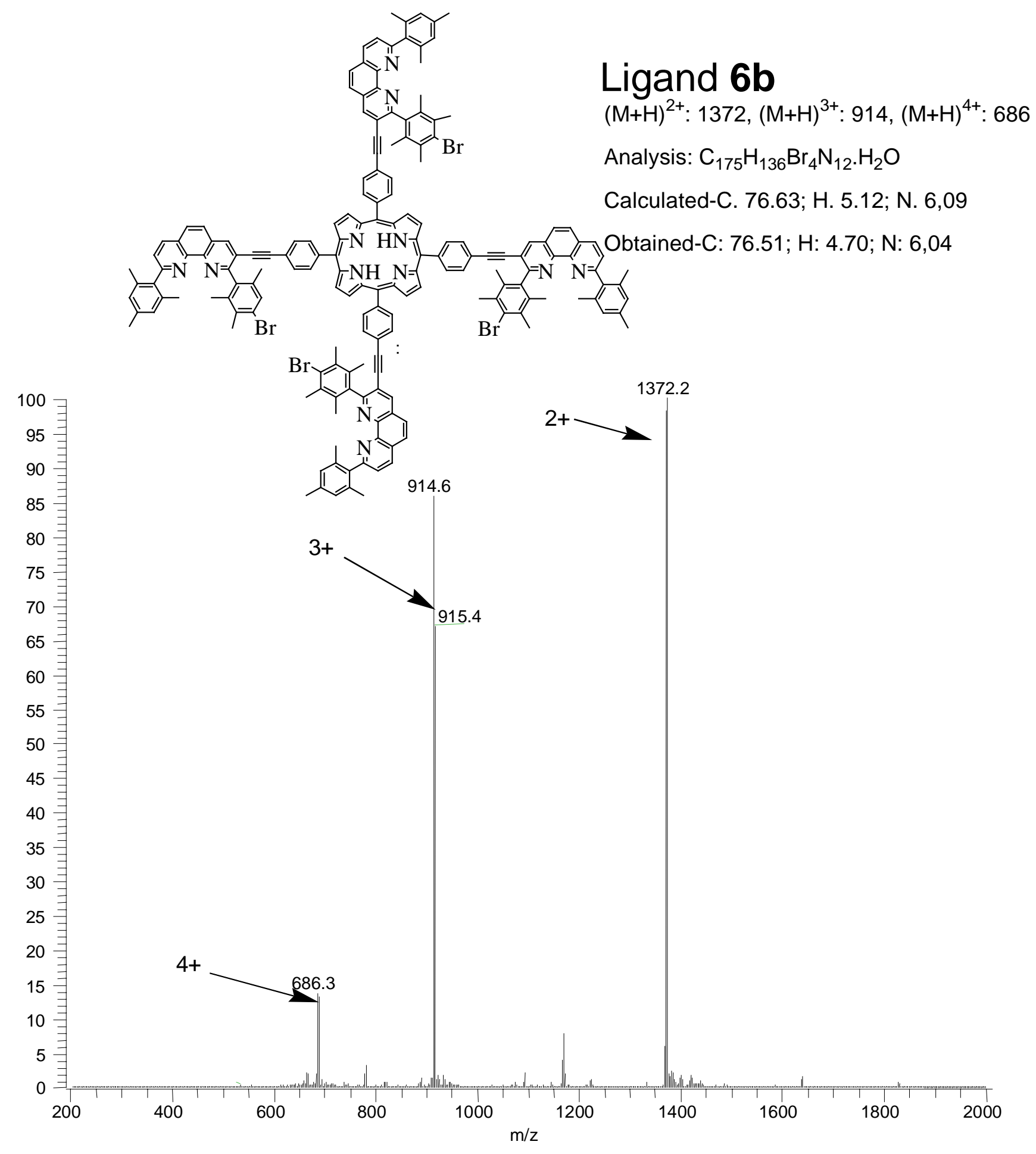




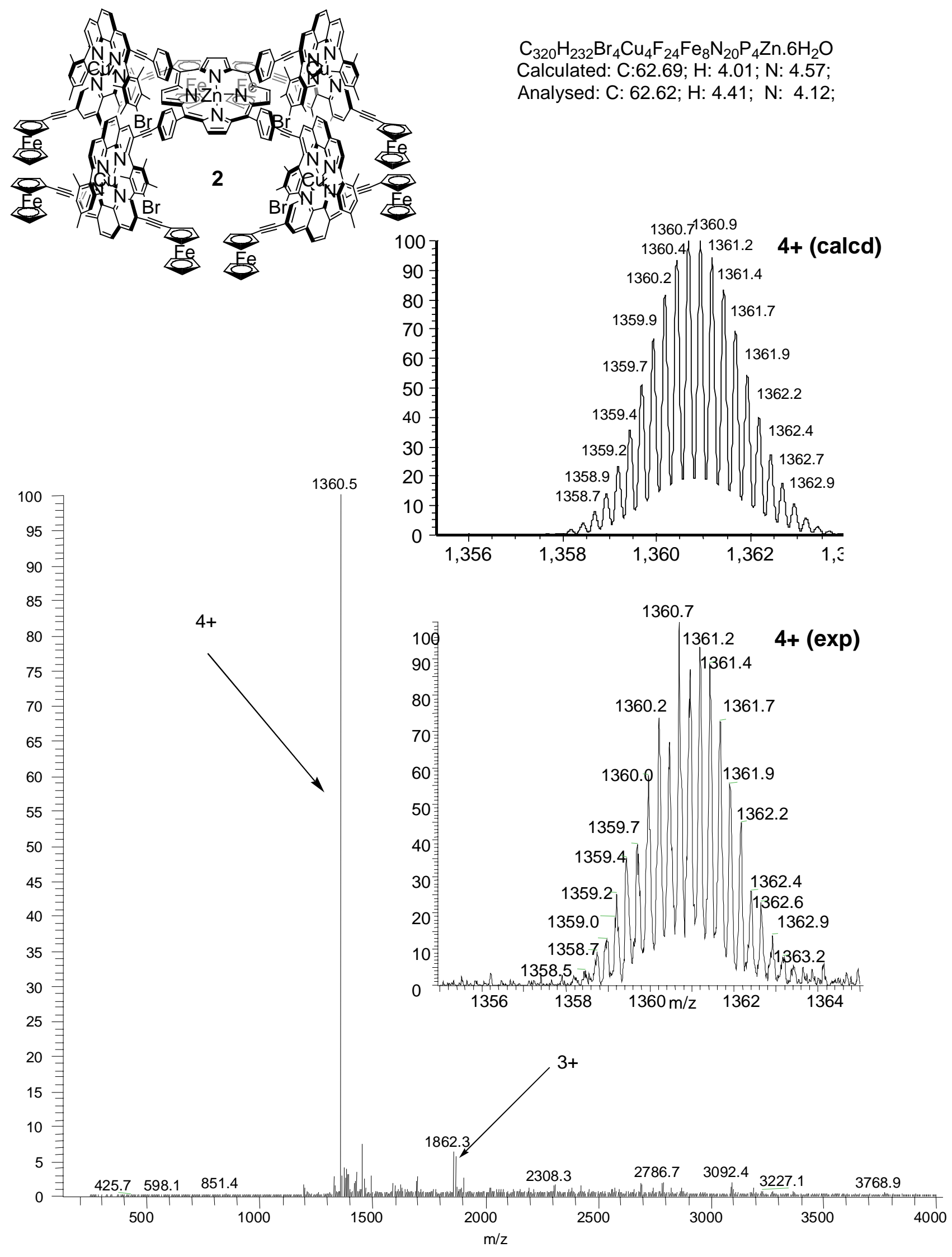




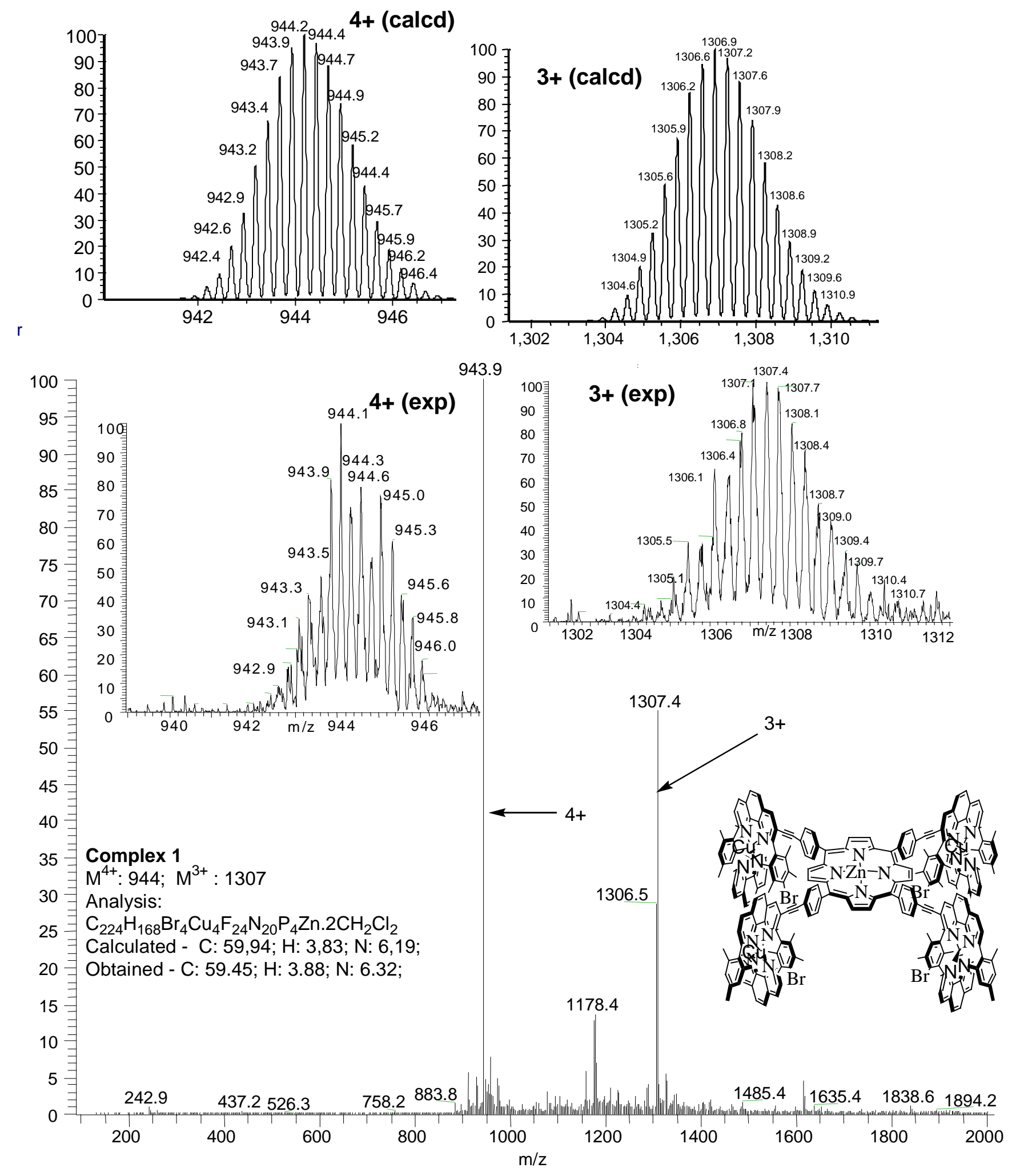

1178.4 ( 3 charged species of loss of one $\mathrm{Cu}+$ and one phenanthroline 

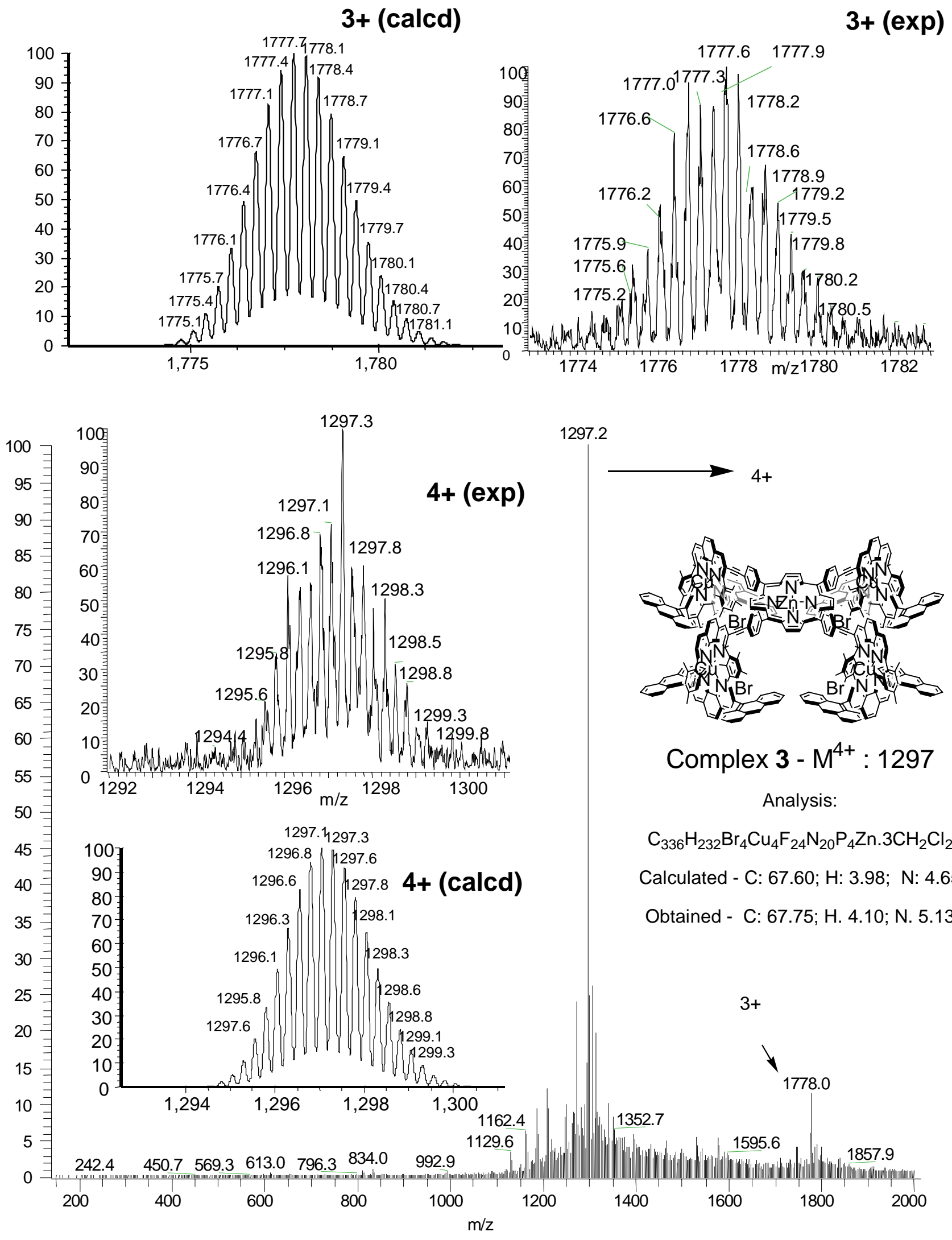


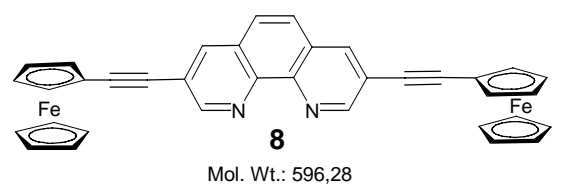

$\mathrm{C}_{36} \mathrm{H}_{24} \mathrm{Fe}_{2} \mathrm{~N}_{2} \cdot 2 \mathrm{H}_{2} \mathrm{O}$

Calculated: C: 68,38 ; $\mathrm{H}: 4,46$; N: 4,43;

Obtained : C: 68,43; H: 4,54; N: 4,14;
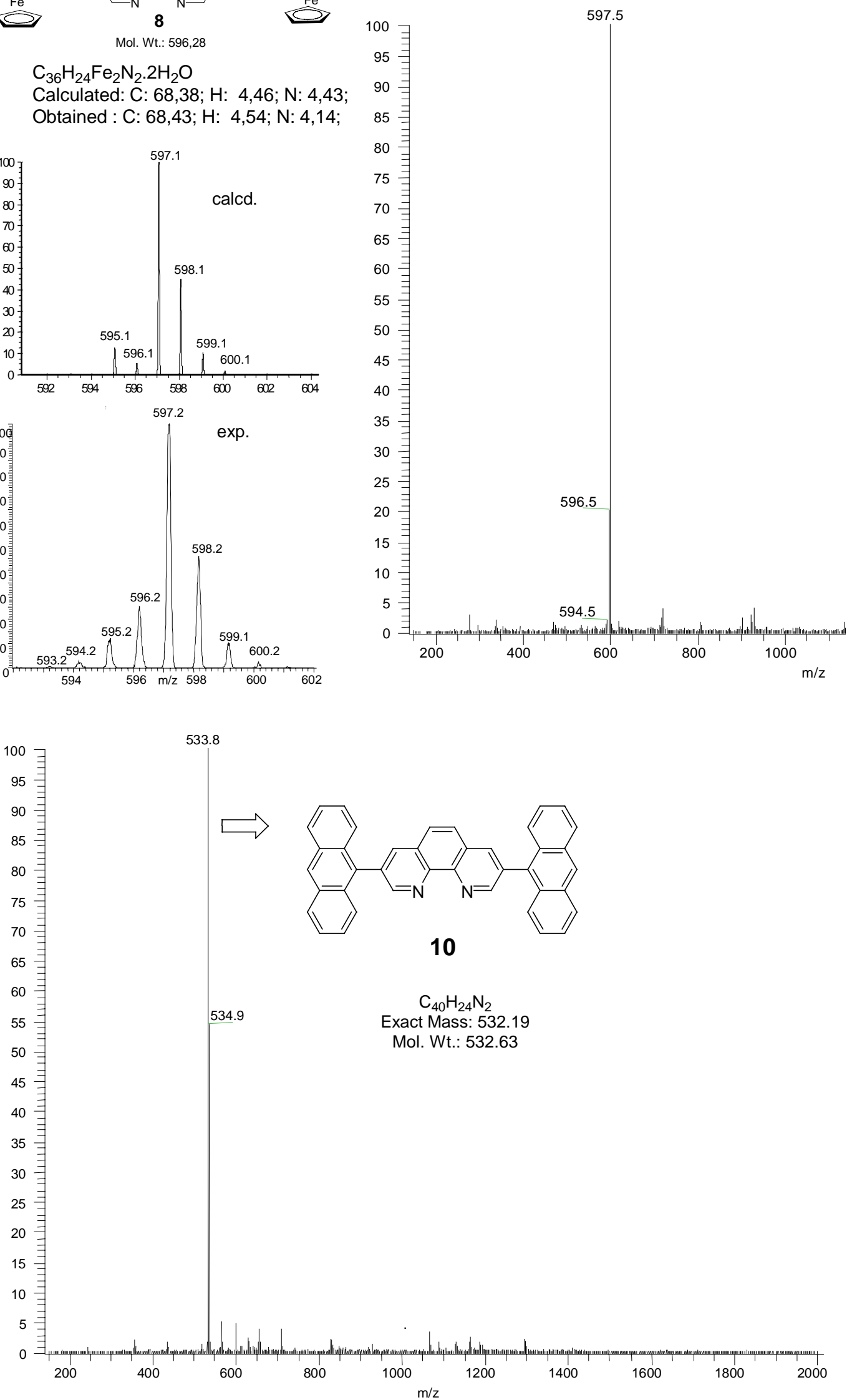


\section{b) UV-vis spectra}

UV-vis of $\mathbf{6 a}(-)$ in comparison with that of precursor porphyrin $5(-)$

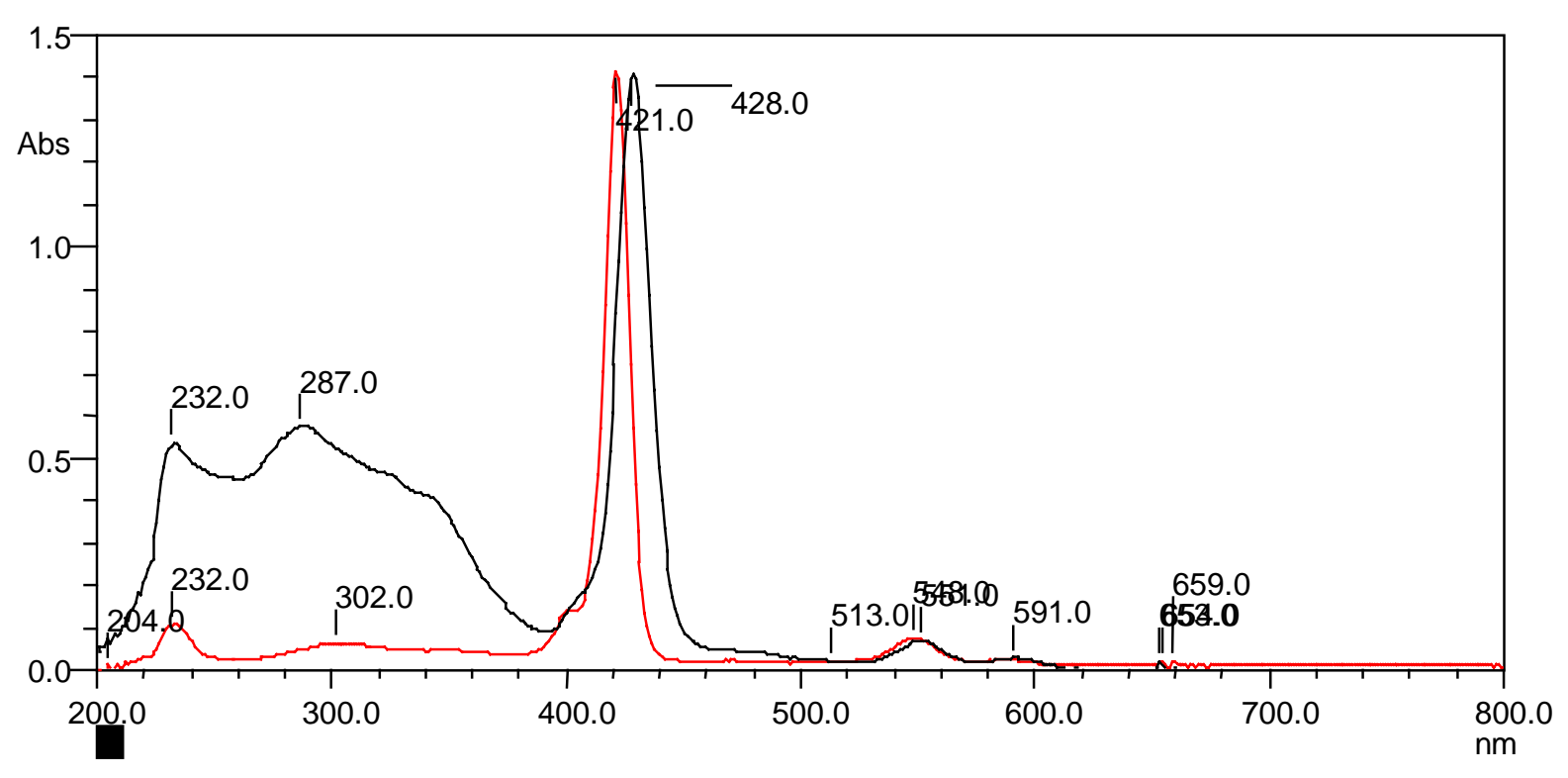

$\mathrm{UV}$-vis spectrum of a titration of $\mathrm{Cu}\left(\mathrm{CH}_{3} \mathrm{CN}\right) \mathrm{PF}_{6}$ against $\mathbf{6 a}$

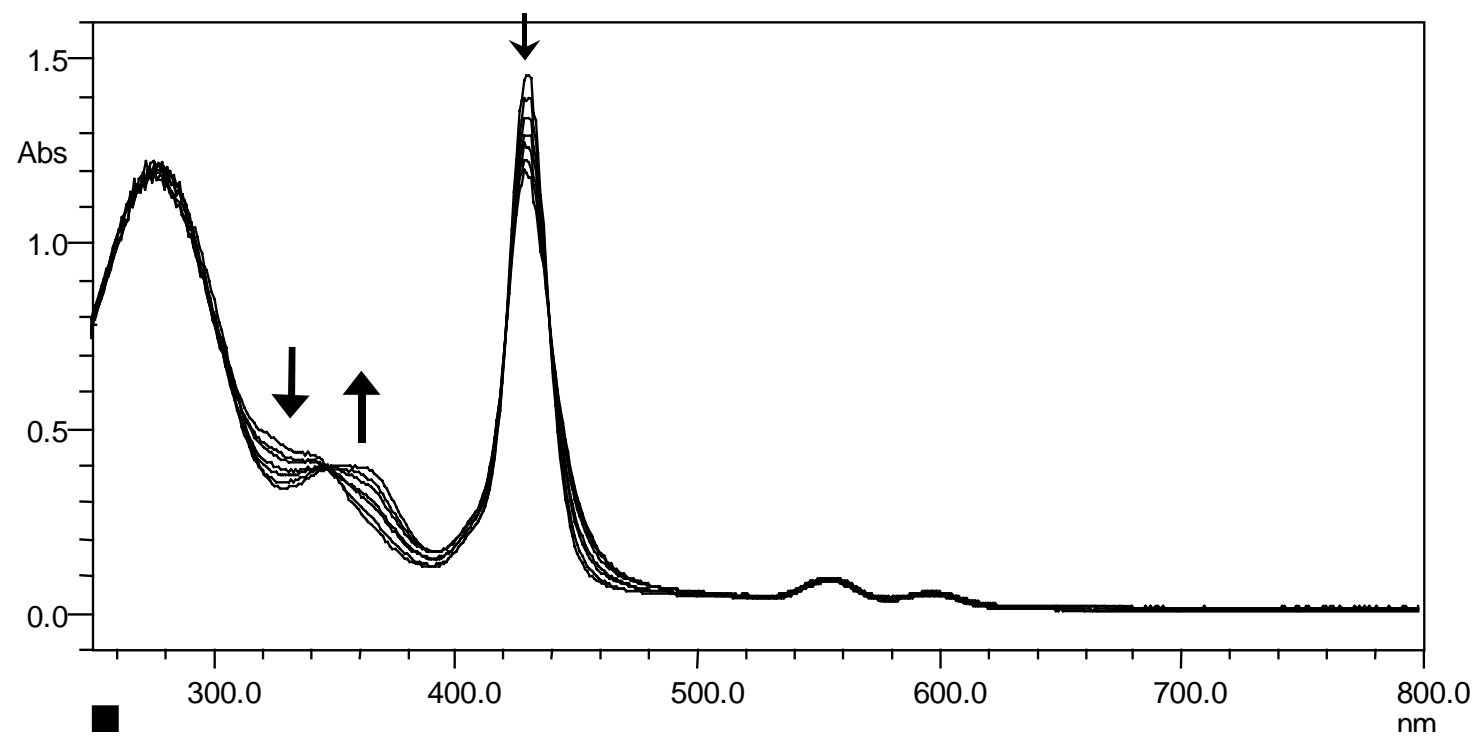




\section{c) Emission spectra}

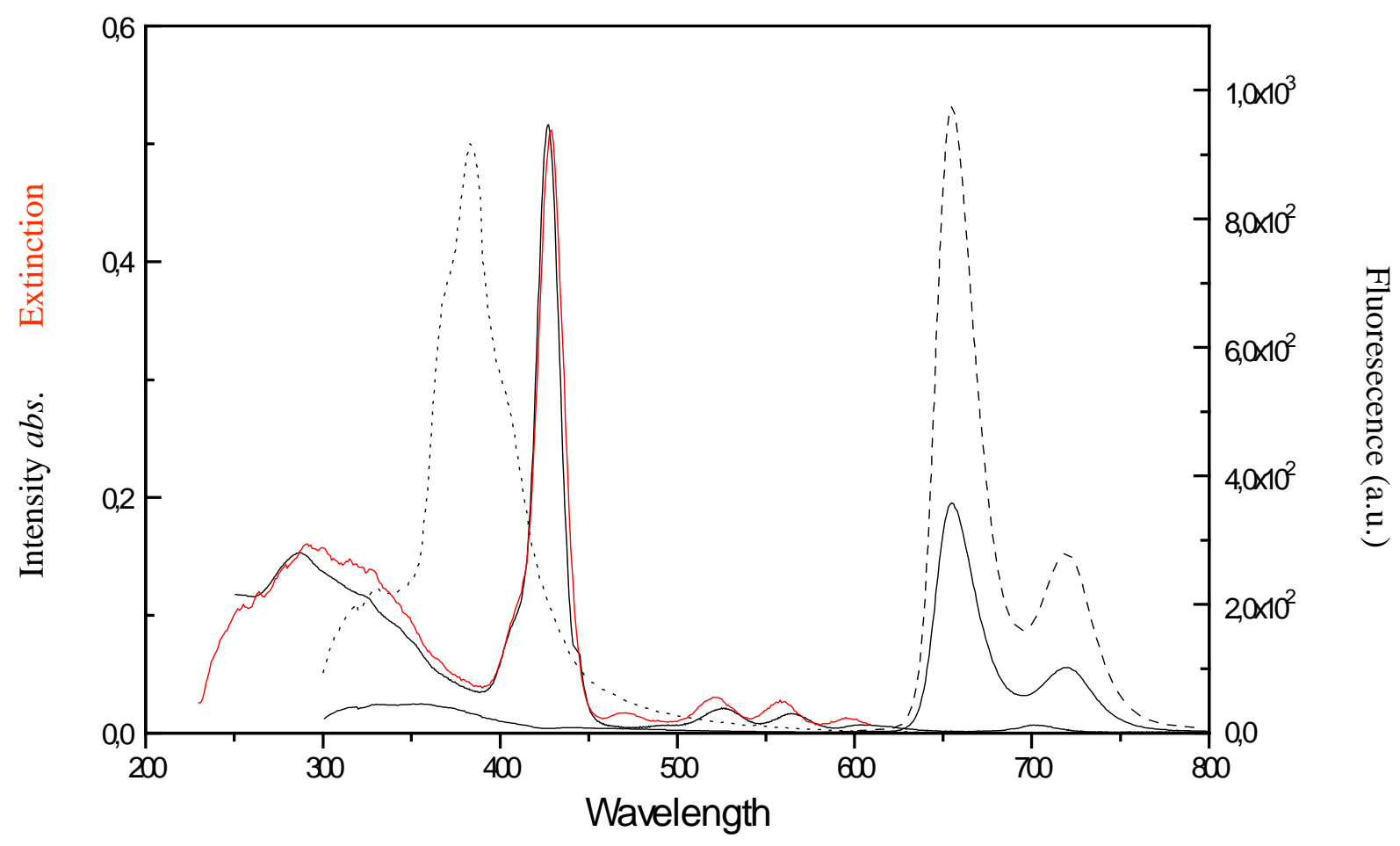

Fluoresence emission spectra of $5(\cdots)$ and $\mathbf{6 a}(-)$ excited at $279 \mathrm{~nm}$ and emission of 6a ( --- ) excited at $426 \mathrm{~nm}$. Absorption spectrum of $\mathbf{6 a}$ in $\mathrm{CH}_{2} \mathrm{Cl}_{2}$ and excitation spectrum of $\mathbf{6 a}(-)$ with emission fixed at $655 \mathrm{~nm}$. 


\section{d) Cyclic voltammograms}

Complex $2: \mathrm{E}_{1 / 2}: 0.56(83), 0.73(91)$
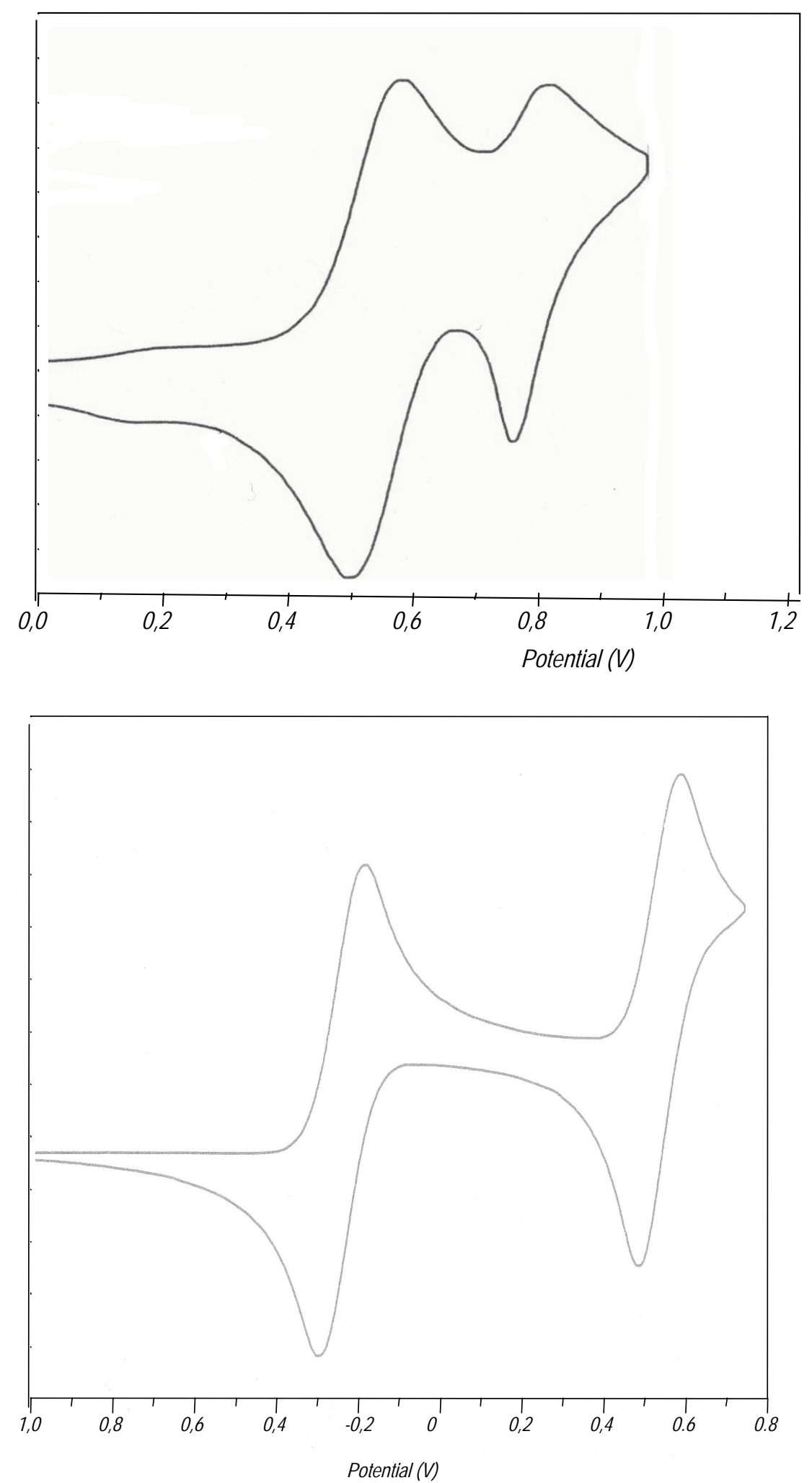

Ligand $8: \mathrm{E}_{1 / 2}=0.53 \mathrm{~V}$ (Standard: decamethylferrocene) 


\section{e) NMR spectra}

Aromatic region in the $\mathrm{H}^{1} \mathrm{NMR}$ of ligand $\mathbf{6 b}$
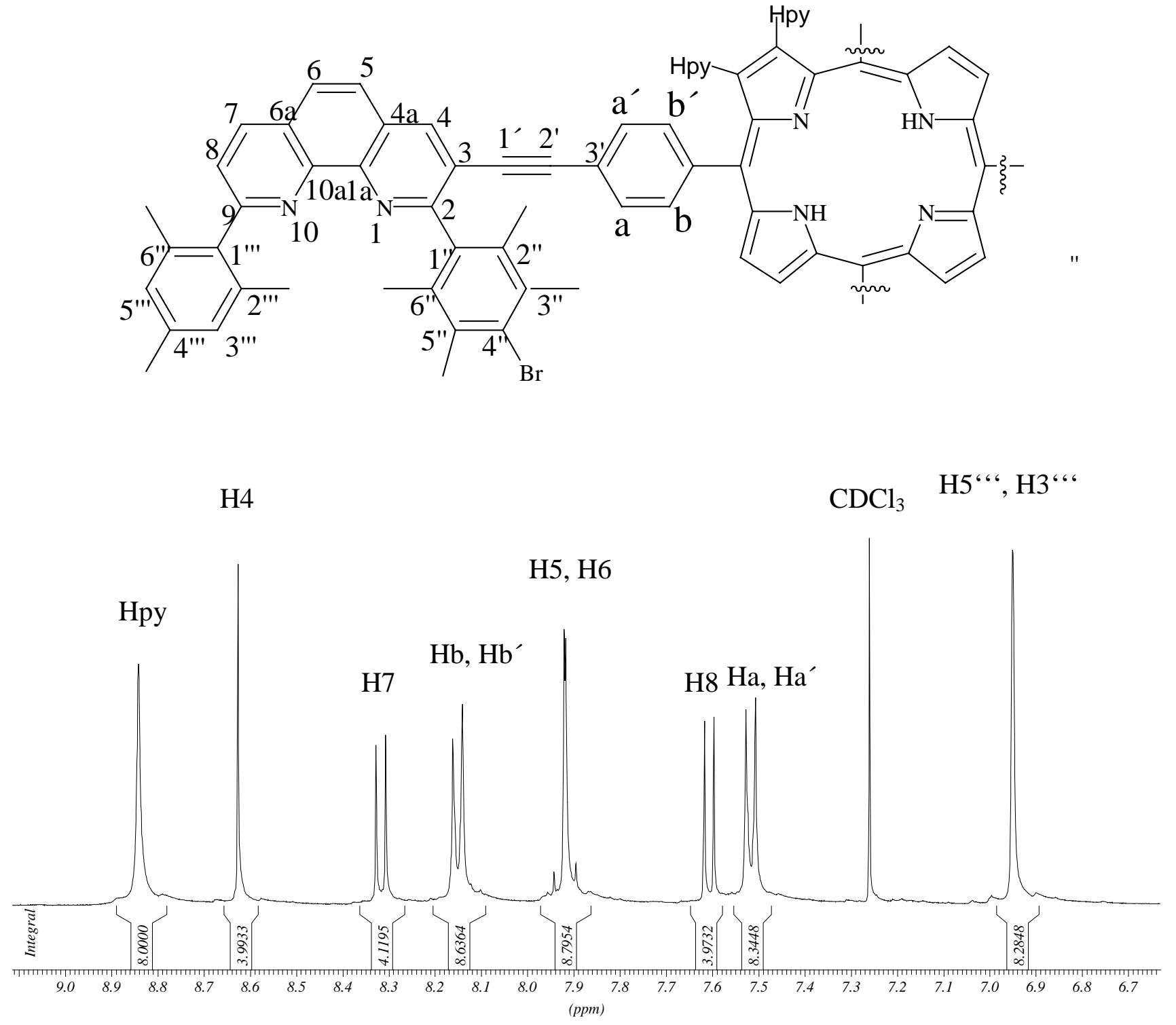


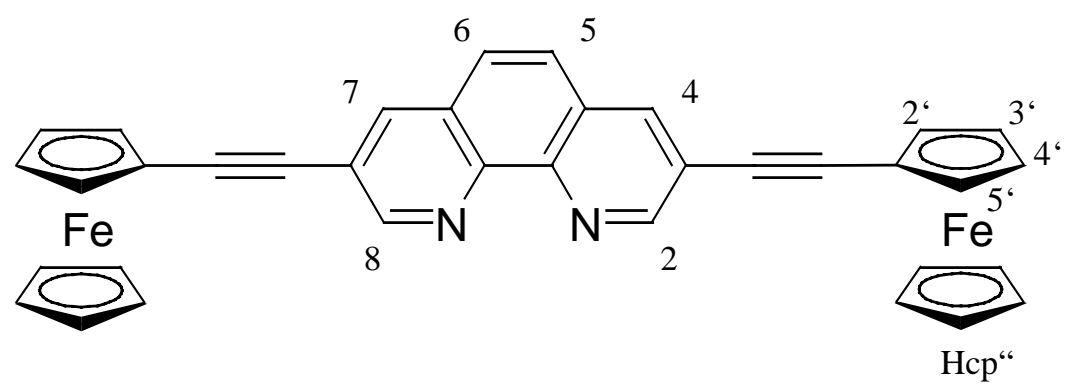

Hсp“

H5, H6
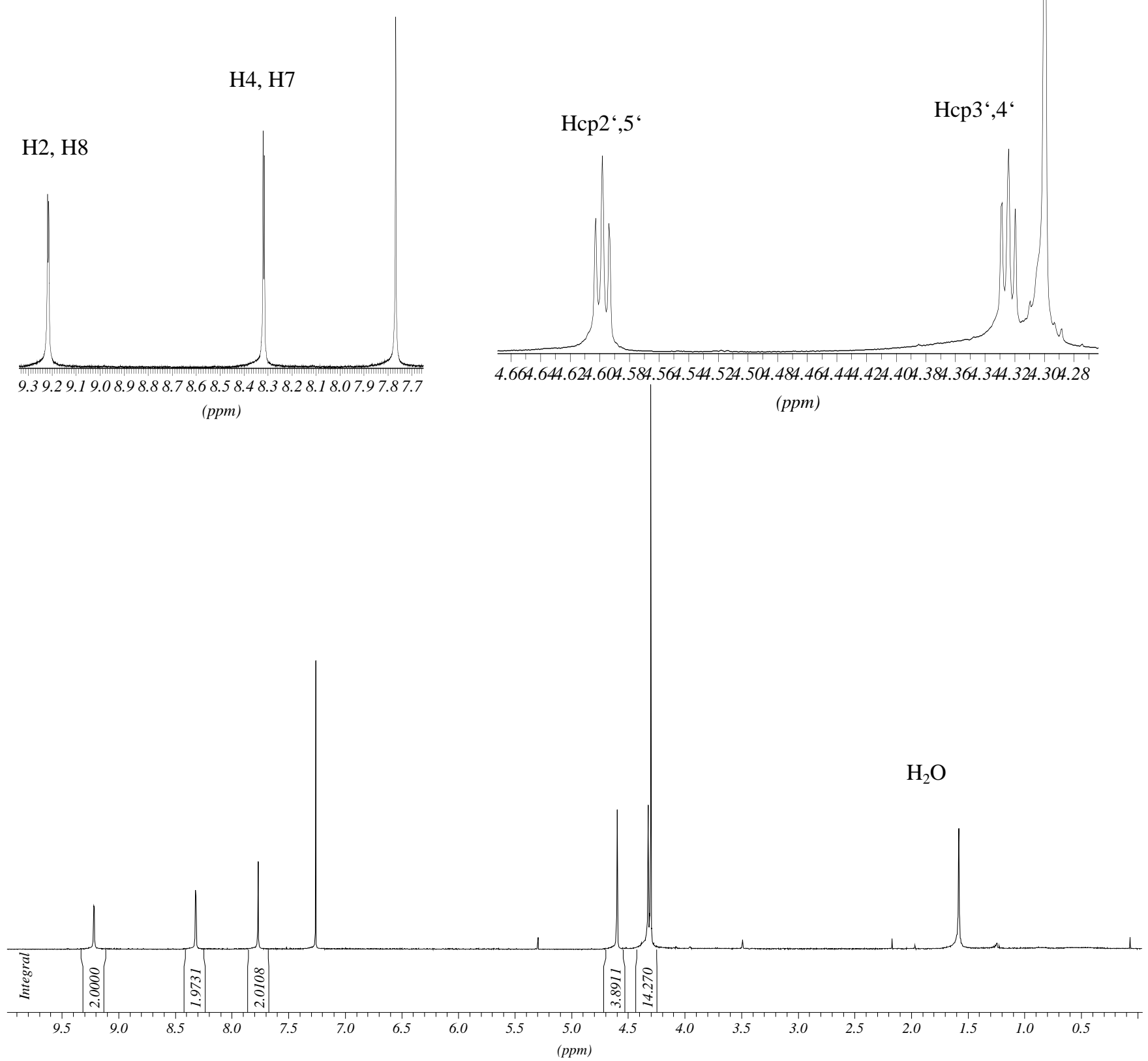


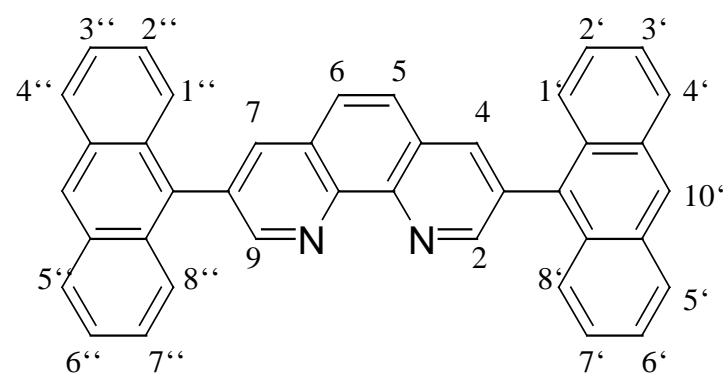

H5, H6

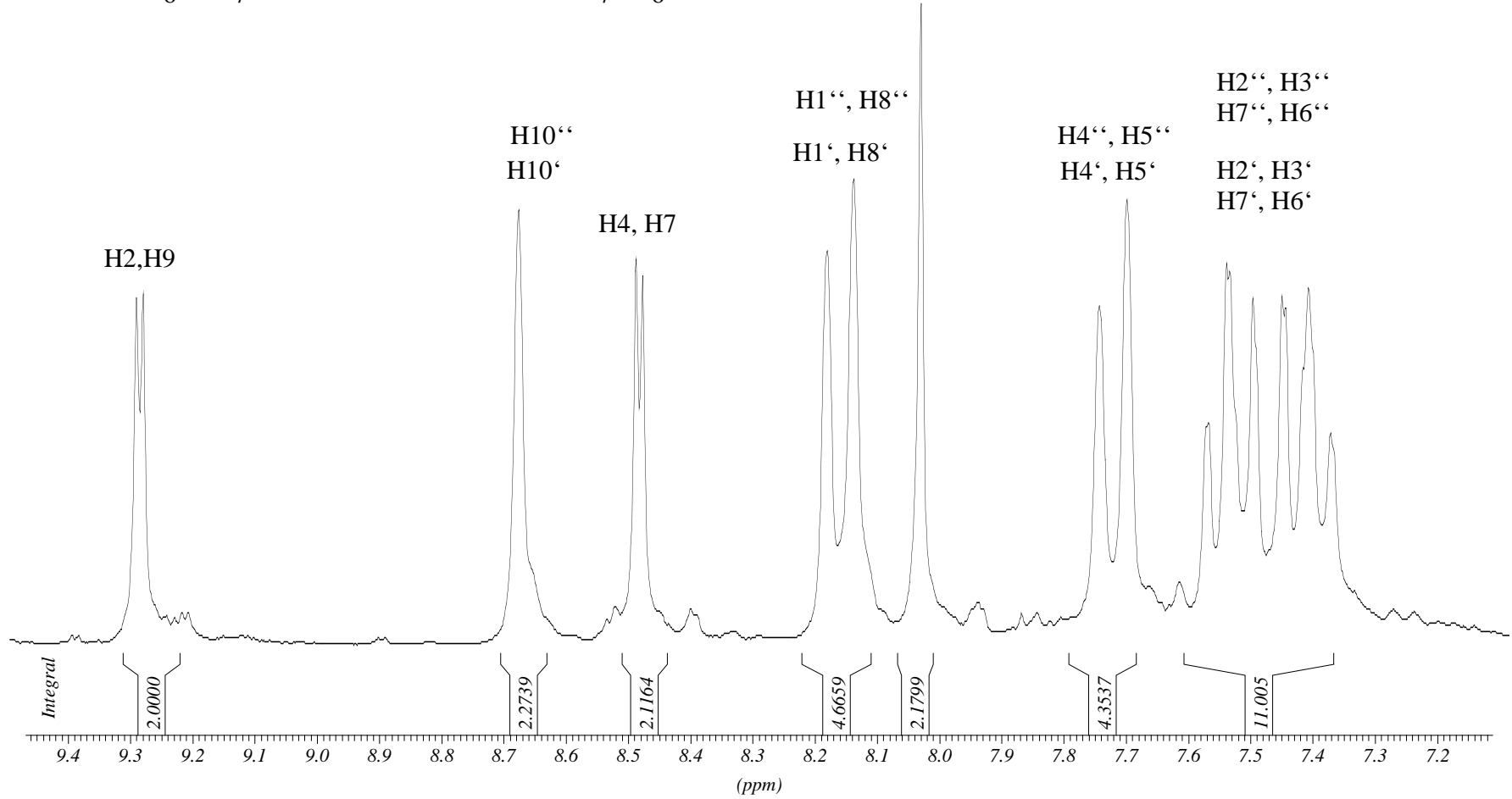


NMR shifts from the ligand $6 \mathbf{a}$ to $\mathrm{Cu}$ containing species $\mathbf{6 a}\left(\mathrm{Cu}^{+}\right)_{4}$ and $\mathbf{1}$ its phenanthroline complex

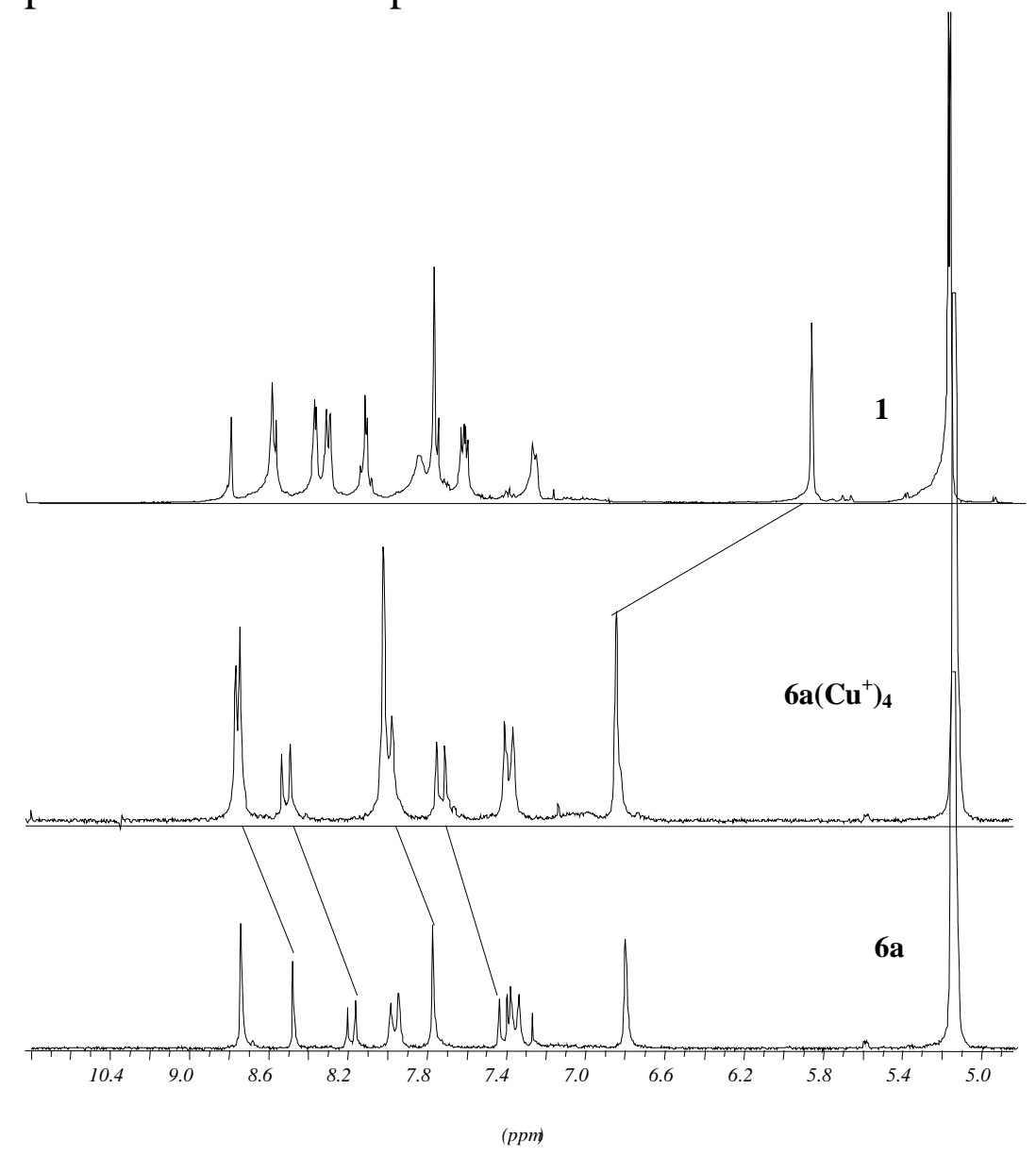

Mesitylene shifts for complexes 1, 2 and $\mathbf{3}$

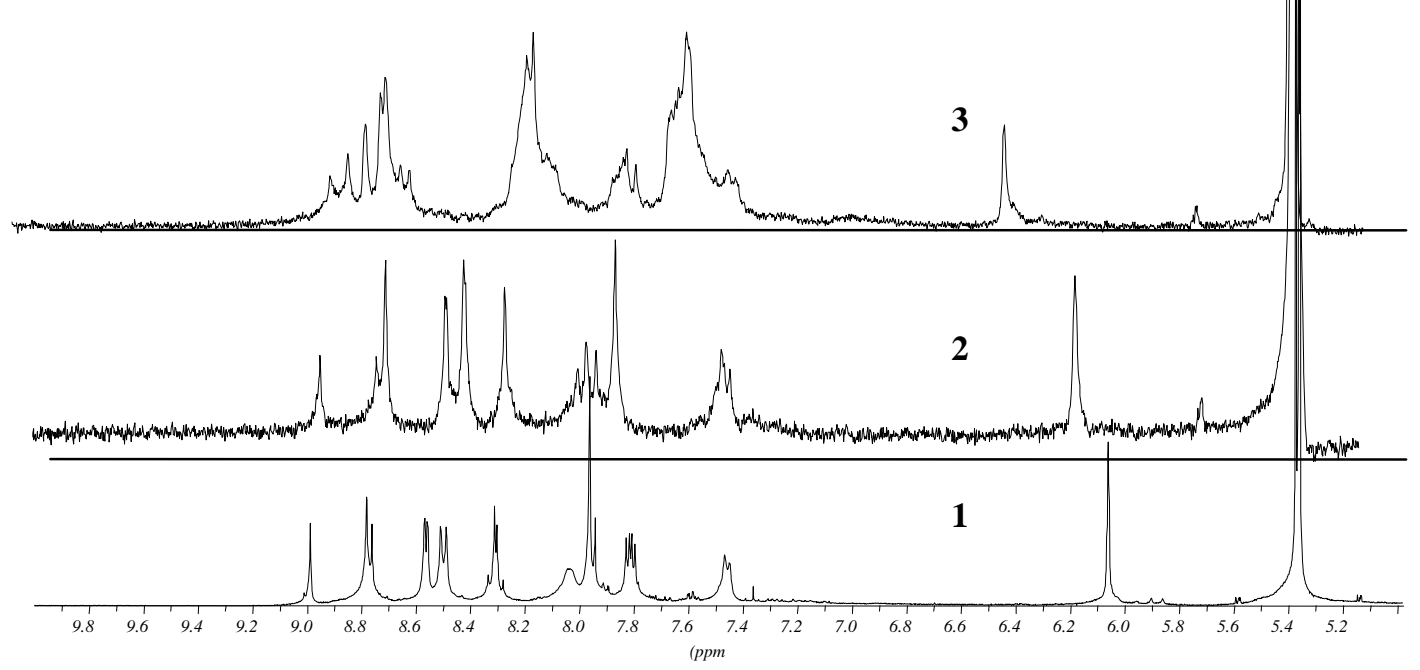

